\title{
Sexually Transmitted Infections (STIs) increased the risk of precancerous cervical lesions among women in Ethiopia: unmatched case-control study
}

Dereje Abebe Teklehaimanot

Debre Berhan Comprehensive Specialized Hospital

Behailu Tariku Derseh ( $\sim$ minastariku@gmail.com )

Debre Berhan University

Abinet Dagnew Mekuria

Debre Berhan University

Abel Fekadu Dadi

University of Gondar

Research Article

Keywords: Cervical pre-cancerous lesions, determinants, oral contraceptives, Ethiopia

Posted Date: February 17th, 2022

DOI: https://doi.org/10.21203/rs.3.rs-1353801/v1

License: @ (i) This work is licensed under a Creative Commons Attribution 4.0 International License.

Read Full License 


\section{Abstract}

Objective: This study aimed to identify the determinants of cervical pre-cancerous lesions among women who attend cervical cancer screening in public health facilities.

Design: An institution-based, unmatched case-control study was conducted among 216 women (54 cases and 162 controls) from January 2020 to April 2020.

Settings: Selected public health facilities in North Shoa Zone, Amhara, Ethiopia.

Participants: Women aged 30 - 49 who were attending cervical cancer screening at health institutions were included in this study.

Outcome measures: Cases were women who attended cervical cancer screening and tested positive for Visual Inspection with Acetic Acid (VIA), whereas controls were women who tested negative for VIA.

Results: Women who used oral contraceptives for more than 5 years were approximately 5 times more likely to develop pre-cancerous lesions (Adjusted Odds Ratio $(A O R)=4.75 ; 95 \% \mathrm{Cl}$ : $1.48,15.30$ ), and early age at first sexual intercourse ( $<15$ years) increased the odds of developing pre-cancerous lesion by 4 fold (AOR $=3.77 ; 95 \% \mathrm{Cl}: 1.46,9.69)$. Women having HIV seropositive results and had a previous history of sexually transmitted infections (STIs) had a 3.4 ( $\mathrm{AOR}=3.45 ; 95 \% \mathrm{Cl}: 1.29,9.25)$ and $2.5(\mathrm{AOR}=2.58 ; 95 \%$ Cl: $1.10,6.09)$ times more odds of developing cervical pre-cancerous lesions than their counterparts.

Conclusions: the use of oral contraceptives for more than five years, early initiation of sex, past and current STI increased the odds of women's developing pre-cancerous cervical lesions. Awareness creation and the National cervical cancer screening program should prioritize women with identified exposures.

\section{Introduction}

Cervical cancer occurs in the female cervical region usually developed after a prolonged phase of preinvasive lesions of the cervix(1). Cervical cancer is primarily caused by persistence and chronic infection of one or more of the monogenic types of human papillomavirus (HPV). Cervical cancer accounted for an estimated 528,000 new cancer cases worldwide and, 266,000 deaths(2). It is associated with high risk sexual behavior, smoking, high alcohol use, family history, and immune-compromised client. However, from the insight of different studies, the etiology of cervical cancer is the most frequent viral origin and it is well understood(3). Unlike other reproductive cancer, this cancer is easily preventable and manageable if it was screened early pre-invasive stage and mass immunization for Human papillomavirus before initiation of sexual intercourse and introduction of effective treatment may benefit the clients and decrease the burden of morbidity and mortality resulting from cervical cancer $(4,5)$.

In sub-Sahara Africa, the burden of cervical cancer was ranging from $7.5 \%$ to $10 \%(6)$. In $2010,20.9$ million women were at risk of developing cervical cancer in Ethiopia with an estimated 4,648 new cases and 3,235 deaths annually $(7,8)$. Cervical cancer is a fully preventable and curable disease through mass 
vaccination at childhood for HPV, interval screening of sexual active women and timely diagnosis of presymptomatic women, treatment and follow-up. But in an advanced stage of the disease, it's difficult to cure and high cost and final death occur(9). Despite its magnitude and impact, there is a lack of information, few screening facility and trained health workers and less attention has been given by policymakers, program manager, health facility, stakeholders, community and family $(10,11)$.

Visual Inspection with Acetic Acid (VIA) is one of the screening modalities of cervical precancerous lesions. Basic knowledge of women's pelvic anatomy and the natural history of cervical cancer give health-care providers the knowledge base to effectively communicate and raise the understanding of cervical cancer prevention in women, families, and communities(12). In the national strategies (20162020), Ethiopia has committed to promote cancer prevention and early detection, and to improve diagnosis and treatment. The strategy also aims to promote cancer research that helps to achieving these goals(13). Identifying risk factors associated with cervical pre-cancerous lesions could help to guide the national strategy in the most efficient direction and enhance the yield of the screening program. Thus, this study was aimed at identifying the predictors of cervical pre-cancerous lesions in the support of the national strategy.

\section{Methods And Materials Study design setting}

We conducted an institution-based unmatched case-control study to assess the determinants of precancerous lesions among women who are attending cervical cancer screening services from January to April 2020. We conducted the study on three hospitals and two health centers that providing pre-cervical cancer screening in North Shoa zone, Amhara regional state of Ethiopia.

\section{Study area and setting}

The study was conducted in North Shoa zone, Amhara regional state of Ethiopia. Debre Berhan, the capital city of the North Shoa Zone, is $695 \mathrm{~km}$ away from Bahir Dar, the capital city of Amhara Regional State, and $130 \mathrm{~km}$ from Addis Abeba, the capital of Ethiopia. The total number of populations in the catchment area is projected to be 2.3 with slightly less than half are females and around $85 \%$ of them living in rural.

\section{Outcome and selection of study participants}

The outcome of the study was pre-cancerous cervical lesion- an abnormal growth of the cells on the surface of the cervix that may exist at any one of the three stages(8). Cases were all selected women aged 30-49 years who underwent pre-cervical lesion screening and tested positive for Visual Inspection with Acetic Acid (VIA) during the study period. Moreover, cases were free of the suspicious lesions with 
VIA, not on menstruation and not pregnant at the time of the study. Controls were all selected women aged 30-49 years who had underwent pre-cervical lesion screening and tested negative for VIA during the study period(8).

The screening has been conducted by trained health professionals (nurses, midwives, physicians, health officers, gynecologists and obstetricians, and emergency surgeons). Health care providers applied diluted acetic acid ( 3 to $5 \%$ ) on a cervix then wait for one minute to decide on the result. When acetic acid applied to the cervix temporarily turns to white (acitowhite) allowing the provider to make an immediate assessment of VIA positive. On the other hand, the presence of smooth and pink uniform features on the cervix indicates the result is negative. Sociodemographic, reproductive and maternal lifestyle and behavioral factors have been collected and investigated as a potential determinant of positive precancerous cervical lesion.

\section{Sample size determination}

We estimated a sample size using Epi Info ${ }^{\mathrm{TM}}$ Team (Epi Info 7.2.0.1, 2016) based on assumptions: (i)twosided confidence level (95\%), power (80\%), case to control ratio (1:3), percentage of controls exposed $(36.68 \%)$, odds ratio (2.55), and percentage of cases with exposure (61.4\%)(14). Based on these, 49 cases, and 147 controls were taken to make the total sample size of 196 . Finally, adding $10 \%$ of nonresponse rate, the total study participants were 216 .

\section{Data collection and analysis}

We used a $5 \%$ pretested and structured interviewer-administered questionnaire to collect the required information using trained data collectors and supervisors.

We checked the collected data for completeness, entered to Epi-Data version 3.1 and then exported to SPSS version 20 for analysis. All variables with $p$-value $<0.2$ were taken into the multivariable model to minimize the possible confounders. We checked for multicollinearity of independent factors using variance inflation factor $(\mathrm{VIF})>10$. The model discrimination capacity was found to be good with the Hosmer-Lemeshow goodness $p$-value of 0.933 . Descriptive finding were presented by frequency, percentage, texts and table. Odds ratio along with $95 \% \mathrm{Cl}$ were estimated to measure the determinants of pre-cancerous cervical lesion by using multivariable logistic regression. Variables significant at p-value less than 0.05 were interpreted as a significant determinant of pre-cancerous cervical lesion.

\section{Result}

\section{Socio demographic characteristics}


The mean $( \pm S D)$ age of respondents was $38.28( \pm 5.85)$ years. Majority $99(61.1 \%)$ of controls and 34 $(63.0 \%)$ of cases were found in the age group of 30-39 years. One fourth $(27.8 \%)$ of the controls and $(31.5 \%)$ of the cases were unable to read and write. Majority $112(69.1 \%)$ of controls and $42(77.8 \%)$ cases were urban residence (Table 1).

Table 1: Socio-demographic characteristics of study participants in North Shoa, Ethiopia, 2020 


\begin{tabular}{|c|c|c|}
\hline Variables & Cases, N (\%) & Controls, N (\%) \\
\hline \multicolumn{3}{|l|}{ Age } \\
\hline 30-39 years & $34(63.0)$ & $99(61.1)$ \\
\hline 40-49 years & $20(37.0)$ & $63(38.9)$ \\
\hline \multicolumn{3}{|l|}{ Level of education } \\
\hline Can't read and write & $17(31.5)$ & $45(27.8)$ \\
\hline Primarily (1-8) & 16(29.6) & $42(25.9)$ \\
\hline Secondary (9-12) & $11(20.4)$ & $32(19.8)$ \\
\hline Diploma and Above & 10(18.5) & $43(26.5)$ \\
\hline \multicolumn{3}{|l|}{ Body mass index } \\
\hline$<18.5$ & $4(7.4)$ & $14(8.6)$ \\
\hline $18.5-24.9$ & $29(53.7)$ & 103(63.6) \\
\hline $25-30$ & $21(38.9)$ & $45(27.8)$ \\
\hline \multicolumn{3}{|l|}{ Wealth index } \\
\hline Poor & $28(51.9)$ & $105(64.8)$ \\
\hline Rich & $26(48.1)$ & $57(35.2)$ \\
\hline \multicolumn{3}{|l|}{ Marital status } \\
\hline Single & $4(7.4)$ & $14(8.6)$ \\
\hline Married & $40(74.1)$ & $125(77.2)$ \\
\hline Widowed & $4(7.4)$ & $11(6.8)$ \\
\hline Divorced & $6(11.1)$ & $12(7.4)$ \\
\hline \multicolumn{3}{|l|}{ Occupation } \\
\hline House wife & $31(57.4)$ & $71(43.8)$ \\
\hline Worker & $23(42.6)$ & $91(56.2)$ \\
\hline \multicolumn{3}{|l|}{ Place of residence } \\
\hline Urban & $42(77.8)$ & $112(69,1)$ \\
\hline Rural & $12(22.2)$ & $50(30.9)$ \\
\hline
\end{tabular}

\section{Reproductive health history}


The magnitude of oral contraceptive user were $112(69.1 \%)$ and $41(75.9 \%)$ among controls and cases. Seventy-seven (47.5\%) of controls and $32(59.3 \%)$ of the cases have seen their first menarche at less than 14 years. Majority $144(88.9 \%)$ of controls and $47(87 \%)$ of cases had history of childbirth. About 144 $(88.9 \%)$ of controls and $47(87 \%)$ of cases had less than five children. Majority 131 (84.6\%) of control and $52(96.3 \%)$ of case had age at first birth between 15 to 24 years (Table 2).

Table 2: Reproductive history among study participants in health facilities, Ethiopia, 2020 


\begin{tabular}{|c|c|c|}
\hline Variables & Cases, N (\%) & Controls, N (\%) \\
\hline \multicolumn{3}{|c|}{ Ever used contraceptive any method } \\
\hline No & $7(13)$ & $22(13.6)$ \\
\hline Yes & $47(87)$ & $140(86.4)$ \\
\hline \multicolumn{3}{|c|}{ How long used oral contraceptives } \\
\hline No & $13(24.1)$ & $50(30.9)$ \\
\hline$<5 y r s$ & $27(50)$ & 102(63.0) \\
\hline$\geq 5 y r s$ & $14(25.9)$ & $10(6.2)$ \\
\hline \multicolumn{3}{|c|}{ Ever used IUCD } \\
\hline No & $14(25)$. & $73(45.1)$ \\
\hline Yes & $40(74.1)$ & $89(54.9)$ \\
\hline \multicolumn{3}{|c|}{ How long used IUCD } \\
\hline No & 14(25.9) & $73((45.1)$ \\
\hline$<5 y r s$ & $20(37)$ & $37(22.8)$ \\
\hline$\geq 5 y r s$ & $20(37)$ & $52(32.1)$ \\
\hline \multicolumn{3}{|c|}{ Pattern of menstrual history } \\
\hline Regular & $32(59.3)$ & $111(68.5)$ \\
\hline Irregular & $22(40.7)$ & $51(31.5)$ \\
\hline \multicolumn{3}{|c|}{ Post coital bleeding } \\
\hline No & $35(64.8)$ & $123(75.9)$ \\
\hline Yes & $19(35.2)$ & $39(24.1)$ \\
\hline \multicolumn{3}{|c|}{ Ever give birth } \\
\hline No & $1(1.9)$ & $6(3.7)$ \\
\hline Yes & $53(98.1)$ & 156(96.3) \\
\hline \multicolumn{3}{|c|}{ Age at first birth } \\
\hline 15-24yrs & $35(29.7)$ & 82(87.3) \\
\hline $25-34 y r s$ & 18(23.3) & $74(68.7)$ \\
\hline \multicolumn{3}{|c|}{ Genital trauma at time of delivery } \\
\hline No & $35(64.8)$ & 122(75.3) \\
\hline
\end{tabular}




\begin{tabular}{|lll|}
\hline Yes & $19(35.2)$ & $40(24.7)$ \\
\hline No trauma & & \\
Vagina & $35(64.8)$ & $122(75.3)$ \\
Both & $4(7.4)$ & $11(6.8)$ \\
\hline Average birth interval & $9(16.7)$ & $20(12.3)$ \\
\hline No & $6(11.1)$ & $9(5.6)$ \\
\hline $1-2 y r s$ & & \\
$\geq 2$ yrs & $4(7.4)$ & $37(37)$ \\
\hline History of Abortion & $29(53.7)$ & $67(41.4)$ \\
\hline No & $21(38.9)$ & $58(35.8)$ \\
Yes & & \\
\hline Family history of cervical cancer & $18(33.3)$ & $82(50.6)$ \\
\hline No & $36(66.7)$ & $80(49.4)$ \\
Yes & $49(90.7)$ & $153(94.4)$ \\
\hline & $5(9.3)$ & $9(5.6)$ \\
\hline
\end{tabular}

\section{Lifestyle and sexual behavior}

Half, $84(51.9 \%)$ of controls and $40(74.1 \%)$ of cases had history of sexual transmitted infections. Many of the cases $45(83.3 \%)$ and 114 (70.4\%) of controls had developed pelvic infection. Twenty-six (16\%) of controls and $19(35.2 \%)$ of cases had started first sexual intercourse at the age of less than 15 years. More than two third 117 (72.2\%) of the controls and $42(77.8 \%)$ of the cases had never used condom during sexual intercourse (Table 3). About 12(7.4) of the controls and 12(22.25) of the cases are HIV positive.

Table 3: Life style and sexual behavior of study participants in North Shoa, Ethiopia, 2020 


\begin{tabular}{|c|c|c|}
\hline Variables & Cases, N (\%) & Controls, N (\%) \\
\hline \multicolumn{3}{|c|}{ Ever screened for cervical cancer } \\
\hline No & $51(94.4)$ & $150(92.6)$ \\
\hline Yes & $3(5.6)$ & $12(7.4)$ \\
\hline \multicolumn{3}{|l|}{ Ever smoked } \\
\hline No & $53(98.1)$ & 159(98.1) \\
\hline Yes & $1(1.9)$ & $3(1.9)$ \\
\hline \multicolumn{3}{|c|}{ Age at first sexual intercourse } \\
\hline$<15 y r s$ & 19(35.2) & 26(16) \\
\hline 15-17yrs & $20(37)$ & $46(28.4)$ \\
\hline$>18 y r s$ & $15(27.8)$ & $90(55.6)$ \\
\hline \multicolumn{3}{|c|}{ Condom used during sexual intercourse } \\
\hline No & $42(77.8)$ & $117(72.2)$ \\
\hline Yes & $12(22.2)$ & $45(27.8)$ \\
\hline \multicolumn{3}{|c|}{ Pelvic infection } \\
\hline No & $9(16.7)$ & $48(29.6)$ \\
\hline Yes & $45(83.3)$ & $114(70.4)$ \\
\hline \multicolumn{3}{|c|}{ History of STI } \\
\hline No & $14(25.9)$ & $78(48.1)$ \\
\hline Yes & $40(74.1)$ & $84(51.9)$ \\
\hline \multicolumn{3}{|c|}{ History of genital ulcer or swelling } \\
\hline No & $43(79.6)$ & 122(75.3) \\
\hline Yes & $11(20.4)$ & $40(24.7)$ \\
\hline \multicolumn{3}{|c|}{ Partner history of genital ulcer } \\
\hline No & $37(68.5)$ & 127(78.4) \\
\hline Yes & 17(31.5) & $35(21.6)$ \\
\hline \multicolumn{3}{|l|}{ HIV status } \\
\hline Reactive & $12(22.2)$ & 12(7.4) \\
\hline Non-reactive & $41(75.9)$ & 134(82.7) \\
\hline
\end{tabular}




\begin{tabular}{|lll|}
\hline Undetermined & $1(1.9)$ & $16(9.9)$ \\
\hline Partner have other partners & & \\
Yes & $16(19.6)$ & $53(32.7)$ \\
\hline
\end{tabular}

\section{Determinants of pre-cancerous cervical lesions among study participants}

Multivariate analysis found the use of oral contraceptives for more than five years (AOR $=4.75 ; 95 \% \mathrm{Cl}$ : $1.48,15.30)$, age of first sexual intercourse at less than 15 years ( $A O R=3.77 ; 95 \% \mathrm{Cl}: 1.46,9.69)$, history of sexually transmitted infections (AOR $=2.63 ; 95 \% \mathrm{Cl}: 1.15,6.00)$, and HIV positive $(\mathrm{AOR}=3.45 ; 95 \% \mathrm{Cl}$ : $1.23,9.25)$ were the determinants of pre-cancerous cervical lesions at $p$-value $<0.05$ (Table 4 ).

Table 4: Bivariable and Multivariable analysis of the determinants of Pre-cancerous lesions among study participants in North Shoa health facilities, Ethiopia, 2020 


\begin{tabular}{|c|c|c|c|c|}
\hline Variables & $\begin{array}{l}\text { Controls, N } \\
(\%)\end{array}$ & $\begin{array}{l}\text { Cases, N } \\
(\%)\end{array}$ & $\operatorname{COR}(95 \% \mathrm{Cl})$ & AOR $(95 \% \mathrm{Cl})$ \\
\hline \multicolumn{5}{|c|}{ Age of first marriage } \\
\hline$<18 y r s$ & $86(53.1)$ & $35(64.8)$ & $1.63(0.86,3.08)$ & $1.87(0.88,3.95)$ \\
\hline$=>18 y r s$ & $76(46.9)$ & 19(35.2) & 1 & 1 \\
\hline \multicolumn{5}{|c|}{ Use of oral contraceptive } \\
\hline No & $50(30.9)$ & $13(24.1)$ & 1 & 1 \\
\hline$<5 y r s$ & $102(63.0)$ & $27(50)$ & $1.02(0.48,2.14)$ & $1.01(0.42,2.42)$ \\
\hline$>5 y r s$ & $10(6.2)$ & $14(25.9)$ & $\begin{array}{l}5.38(1.95 \\
14.86)\end{array}$ & $\begin{array}{l}4.75 \\
(1.47,15.30) *\end{array}$ \\
\hline$>15 y r s$ & $85(52.5)$ & $22(40.7)$ & 1 & 1 \\
\hline \multicolumn{5}{|c|}{ Age of first birth } \\
\hline $15-24 y r s$ & $82(87.3)$ & $35(29.7)$ & $0.57(.29,1.09)$ & $0.78(0.67,1.68)$ \\
\hline $25-34 y r s$ & $74(68.7)$ & $18(23.3)$ & 1 & 1 \\
\hline \multicolumn{5}{|c|}{ Average birth interval } \\
\hline No & $37(37)$ & $4(7.4)$ & 1 & 1 \\
\hline $1-2 y r s$ & $67(41.4)$ & $29(53.7)$ & $4.01(1.31,12.27)$ & $1.75(0.42,7.27)$ \\
\hline$\geq 2 \mathrm{yrs}$ & $58(35.8)$ & 21(38.9) & $\begin{array}{l}3.349(1.06 \\
10.54)\end{array}$ & $1.61(0.36,7.27)$ \\
\hline \multicolumn{5}{|c|}{ History of abortion } \\
\hline No & $82(50.6)$ & 18(33.3) & 1 & 1 \\
\hline Yes & $80(49.4)$ & $36(66.7)$ & $2.05(1.07,3.91)$ & $1.57(0.67,3.67)$ \\
\hline \multicolumn{5}{|c|}{$\begin{array}{l}\text { Age of first sexual } \\
\text { intercourse }\end{array}$} \\
\hline$<15 y r s$ & $26(16)$ & 19(35.2) & $4.38(1.96,9.81)$ & $3.77(1.46,9.69)^{\star}$ \\
\hline $15-17 y r s$ & $46(28.4)$ & $20(37)$ & $2.61(1.22,5.57)$ & $2.58(1.09,6.08)^{\star}$ \\
\hline$>18 y r s$ & $90(55.6)$ & $15(27.8)$ & 1 & 1 \\
\hline \multicolumn{5}{|c|}{ Pelvic Infection } \\
\hline No & 48(29.6) & $9(16.7)$ & 1 & 1 \\
\hline Yes & 114(70.4) & 45(83.3) & $2.11(0.95,4.64)$ & $0.76(0.22,2.73)$ \\
\hline
\end{tabular}




\begin{tabular}{|c|c|c|c|c|}
\hline No & 78(48.1) & $14(25.9)$ & 1 & 1 \\
\hline Yes & $84(51.9)$ & $40(74.1)$ & $2.65(1.34,5.25)$ & $2.63(1.15,6.01) *$ \\
\hline \multicolumn{5}{|c|}{ The result HIV } \\
\hline \multirow{3}{*}{$\begin{array}{l}\text { Positive } \\
\text { Unknown } \\
\text { Negative }\end{array}$} & $12(7.4)$ & $12(22.2)$ & $3.27(1.36,7.83)$ & $\begin{array}{l}3.45(1.29 \\
9.25)^{\star}\end{array}$ \\
\hline & 16(9.9) & $1(1.9)$ & $0.20(0.03,1.58)$ & $0.43(0.05,3.75)$ \\
\hline & $134(82.7)$ & $41(75.9)$ & 1 & 1 \\
\hline
\end{tabular}

Note: *indicates significant variables at $p$-value $<0.05$

\section{Discussion}

Early detection and treatment of pre-cancerous cervical lesions is critical to prevent the progression of cervical cancer. We developed a model that would help clinicians to prioritize women at higher risk of developing pre-cancerous cervical lesions for screening. These women are those who have used oral contraceptive for more than five years, had history of early (before age 15 years) initiation of sexual intercourse, and had sexually transmitted infections including HIV/AIDS.

The odds of developing pre-cancerous cervical lesions among women who used oral contraceptives for more than five years were 4 times higher than women who had not used oral contraceptives. This finding were consistent with the study conducted in Ethiopia(15), Indonesia(16), and Thailand(17). Prolonged use of oral contraceptive hormones may increase eversion of the columnar epithelium to the ectocervices that enhance the exposure of the columnar epithelium to HPV infection(18).

Early initiation of sexual intercourse is associated with increased odds of acquiring pre-cancerous cervical lesions. We found that women who initiated sexual intercourse before 15 years were 3 times more likely to develop pre-cancerous cervical lesions than women who started sexual intercourse after 18 years. This finding was consistent with the study conducted in Ethiopia(15,19) and Rwanda(20).Moreover, the odds of developing pre-cancerous cervical lesions among women who initiated sexual intercourse in between 15 - 17 years were 2 times higher when compared to women with age greater than 18 years and the finding is consistent with other study conducted in Ethiopia(21). Most of the time sexual practice is performed with aged partners and practicing early sex could probably increases the risks of Human Papiloma Virus (HPV) infection deu to a biological predisposition of premature cervix in the early age.

Sexually Transmitted Infections (STIs) were another determinant factor for the development of precancerous cervical lesions among women in this study. The odds of developing pre-cancerous cervical lesion among women with history of sexually transmitted infections were 2.6 times higher than women who had no history of STIs. This finding was consistent with the studies conducted in Ethiopia $(11,22)$, 
Egypt(23), and Moroco(24). The association would be potentially explained by co-infection of HPV with other STIs. Similarly, an increased odd of pre-cancerous cervical lesion was observed among HIV positive women than HIV negative women suggesting that Immuno-compromised women should take cervical cytological examination, annually. As previous study conducted on the intention of cervical cancer screening among women was low, a lot has to be done to enhance the intention and uptake of screening. This finding is consistent with the study conducted in Ethiopia(25), Tanzania(26), and Côte d'Ivoire(27). The possible explanation might be immune suppression, and easily attacks to human papilloma virus aggravate the pre-cervical cancer.

\section{Limitations of the Study}

The results of this study should be interpreted by considering the following limitations. Some participants may not disclose their actual problem during history taking and data collection from cultural and reduced literacy. However, to reduce under estimation of the findings, data collectors have been trained intensively for 10 days to gather relevant information by explaining the purpose of the study and provide genuine answers. Consequently, recall and social desirability bias were reduced.

\section{Conclusions And Recommendation}

In conclusion, women who used oral contraceptives for more than five years, started sexual intercourse before 15 years, had history of sexual transmitted infections, and HIV positive women were more likely to have pre-cancerous cervical lesion. Hence health institutions should develop targeted intervention strategies for behavioral change communication to prevent and control early sexual behavior and sexually transmitted infections, thereby prevent cervical pre-cancerous lesions. More importantly, the concept of life-course principles should be introduced for female adolescents as early as possible. This approach recognizes the opportunity to prevent and control diseases at key stage in life from preconception to adulthood going through all developmental stages.

\section{Declarations}

\section{Author's contribution}

All authors conceived and designed the study, acquired, analyzed and interpreted data, prepared the manuscript and approved the final manuscript, equally.

\section{Acknowledgements}

We would like to extend our heartfelt gratitude to study participants, data collectors, health facilities managers, and Debre Berhan University for their efforts, time, and support.

\section{Competing interests}

The authors declare that we have no competing interests. 
Availability of data and materials

All the required data for this article has been included in the tables.

\section{Consent for publication}

Not applicable.

\section{Ethics approval statement}

Ethical clearance letter and approval was obtained from Debre Berhan University Postgraduate Research Ethics Committee (PGREC) - (Protocol number: 29/12/SPH). Permission and letter of support were obtained from each health facilities. Study participants were informed about the purpose of the study, their voluntariness to participation, and the right to withdraw (stop) the study at any time when they feel uncomfortable. To assure the confidentiality of the participants unique identifiers are not included in the data.

\section{Funding}

Funding is not issued for the publication of this article.

\section{References}

1. Reddy KS. Global Burden of Disease Study 2015 provides GPS for global health 2030. Lancet. 2016;388(10053):1448-9.

2. Asseffa NA. Cervical Cancer: Ethiopia's Outlook. J Gynecol Womens Heal [Internet]. 2017 Jun 1;5(2). Available from: https://juniperpublishers.com/jgwh/JGWH.MS.ID.555660.php

3. Momenimovahed Z, Salehiniya H. Incidence, mortality and risk factors of cervical cancer in the world. Biomed Res Ther [Internet]. 2017 Dec 8;4(12):1795. Available from:

http://www.bmrat.org/index.php/BMRAT/article/view/386

4. Botelho MC, Alves H, Richter J, Diseases C, Herculano RA, Health I. HHS Public Access. 2017;14(Estrogen catechols detection as biomarkers in schistosomiasis induced cancer and infertility):135-8.

5. Converse PJ, Mariam DH, Mulatu M, Mekonnen W, Kloos H. Bibliography on HIV / AIDS in Ethiopia and Ethiopians in the Diaspora: The 2012 Update. 2012;

6. Bruni L, Barrionuevo-Rosas L, Albero G, Serrano B, Mena M, Gómez D, et al. Human Papillomavirus and Related Diseases Report in the World: Summary Report. HPV Information Centre. 2017.

7. World Health Organization. Cervical cancer [Internet]. 2017. Available from: https://www.who.int/health-topics/cervical-cancer\#tab=tab_1 
8. Federal Democratic Republic of Ethiopia Health M of H. Guideline for Cervical Cancer Prevention and Control in Ethiopia. 2019.

9. EFMOH. NATIONAL CANCER CONTROL PLAN 2016-2020. 2020;(October 2015).

10. Ntekim A. Cervical Cancer in Sub Sahara Africa. In: Topics on Cervical Cancer With an Advocacy for Prevention [Internet]. InTech; 2012. Available from: http://www.intechopen.com/books/topics-on-cervicalcancer-with-an-advocacy-for-prevention/cervical-cancer-in-sub-sahara-africa

11. Tadesse SK. Preventive Mechanisms and Treatment of Cervical Cancer in Ethiopia. Gynecol Obstet. 2017; s3.

12. WHO. Comprehensive Cervical Cancer Control. Geneva. 2014;366-78.

13. Federal Ministry of Health, ETHIOPIA. NATIONAL CANCER CONTROL PLAN 2016-2020 [Internet]. Addis Ababa; 2015. Available from: https://www.iccp-portal.org/sites/default/files/plans/NCCP Ethiopia Final 261015.pdf

14. Getachew S, Getachew E, Gizaw M, Ayele W, Addissie A, Kantelhardt EJ. Cervical cancer screening knowledge and barriers among women in Addis Ababa, Ethiopia. Naanyu V, editor. PLoS One [Internet]. 2019 May 10;14(5):e0216522. Available from: https://dx.plos.org/10.1371/journal.pone.0216522

15. Kassa RT. Risk factors associated with precancerous cervical lesion among women screened at Marie Stops Ethiopia, Adama town, Ethiopia 2017: a case control study. BMC Res Notes [Internet]. 2018 Dec 20;11(1):145. Available from: https://bmcresnotes.biomedcentral.com/articles/10.1186/s13104-018$3244-6$

16. Wahidin M, Djuwita R, Adisasmita A. Oral Contraceptive and Breast Cancer Risks: a Case Control Study in Six Referral Hospitals in Indonesia. 2018;19:2199-203.

17. Marks MA, Gupta S, Liaw KL, Tadesse A, Kim E, Phongnarisorn C, et al. Prevalence and correlates of HPV among women attending family-planning clinics in Thailand. BMC Infect Dis. 2015;15(1).

18. Bright PL, Norris Turner A, Morrison CS, Wong EL, Kwok C, Yacobson I, et al. Hormonal contraception and area of cervical ectopy: a longitudinal assessment. Contraception [Internet]. 2011 Nov;84(5):512-9. Available from: https://linkinghub.elsevier.com/retrieve/pii/S0010782411000540

19. Getinet M, Gelaw B, Sisay A, Mahmoud EA, Assefa A. Prevalence and predictors of Pap smear cervical epithelial cell abnormality among HIV-positive and negative women attending gynecological examination in cervical cancer screening center at Debre Markos referral hospital, East Gojjam, Northwest Ethiopia. BMC Clin Pathol [Internet]. 2015 Dec 23;15(1):16. Available from: http://bmcclinpathol.biomedcentral.com/articles/10.1186/s12907-015-0016-2 
20. Makuza JD, Nsanzimana S, Muhimpundu MA, Pace LE, Ntaganira J, Riedel DJ. Prevalence and risk factors for cervical cancer and pre-cancerous lesions in Rwanda. Pan Afr Med J [Internet]. 2015;22:26. Available from: http://www.ncbi.nlm.nih.gov/pubmed/26664527

21. Hailemariam T, Yohannes B, Aschenaki H, Mamaye E, Orkaido G, Seta M. Prevalence of Cervical Cancer and Associated Risk Factors among Women Attending Cervical Cancer Screening and Diagnosis Center at Yirgalem General Hospital, Southern Ethiopia. J Cancer Sci Ther [Internet]. 2017;9(11):730-5. Available from: https://www.omicsonline.org/open-access/prevalence-of-cervical-cancer-and-associatedrisk-factors-among-women-attending-cervical-cancer-screening-and-diagnosis-center-at-1948-59561000500-96285.html

22. Geremew AB, Gelagay AA, Azale T. Comprehensive knowledge on cervical cancer, attitude towards its screening and associated factors among women aged 30-49 years in Finote Selam town, northwest Ethiopia. Reprod Health [Internet]. 2018 Feb 14;15(1):29. Available from:

http://www.ncbi.nlm.nih.gov/pubmed/29444689

23. El-Moselhy EA, H.M. B, Altam SA. Cervical Cancer: Sociodemographic and Clinical Risk Factors Among Adult Egyeptian Females. J Oncol Res Treat. 2020;5(2):1-7.

24. Berraho M, Amarti-Riffi A, El-Mzibri M, Bezad R, Benjaafar N, Benideer A, et al. HPV and cofactors for invasive cervical cancer in Morocco: a multicentre case-control study. BMC Cancer [Internet]. 2017 Dec 20;17(1):435. Available from: http://bmccancer.biomedcentral.com/articles/10.1186/s12885-017-3425-z

25. Temesgen K, Workie A, Dilnessa T, Abate M. Proportions of Pre-Cancerous Cervical Lesions and Its Associated Factors among Women Clients in the Age Group of 30-49yrs in Gynecology Ward of Dessie Referral Hospital and FGAE, North-East Ethiopia, 2016. J Cancer Tumor Int. 2019;9(2):1-15.

26. Chambuso RS, Shadrack S, Lidenge SJ, Mwakibete N, Medeiros RM. Influence of HIV/AIDS on Cervical Cancer: A Retrospective Study From Tanzania. J Glob Oncol [Internet]. 2017 Feb;3(1):72-8. Available from: https://ascopubs.org/doi/10.1200/JG0.2015.002964

27. Adjorlolo-Johnson G, Unger ER, Boni-Ouattara E, Touré-Coulibaly K, Maurice C, Vernon SD, et al. Assessing the relationship between HIV infection and cervical cancer in Côte d'Ivoire: a case-control study. BMC Infect Dis [Internet]. 2010 Aug 17;10:242. Available from:

http://www.ncbi.nlm.nih.gov/pubmed/20716343 